\title{
Author Correction: Nanometric axial localization of single fluorescent molecules with modulated excitation
}

Pierre Jouchet (D), Clément Cabriel(D), Nicolas Bourg (D), Marion Bardou (D), Christian Poüs, Emmanuel Fort (D) and Sandrine Lévêque-Fort (iD

Correction to: Nature Photonics https://doi.org/10.1038/s41566-020-00749-9, published online 25 January 2021.

In the version of this Article originally published, the units of the colour scales in Fig. 4a,b,d-f were incorrectly given as nm; they should have been $\mu \mathrm{m}$. This has now been corrected in all versions of the Article.

Published online: 1 February 2021

https://doi.org/10.1038/s41566-021-00767-1

(c) The Author(s), under exclusive licence to Springer Nature Limited 2021

\section{Publisher Correction: Nanometric axial localization of single fluorescent molecules with modulated excitation}

Pierre Jouchet (D), Clément Cabriel(D), Nicolas Bourg (D), Marion Bardou (D), Christian Poüs, Emmanuel Fort (D) and Sandrine Lévêque-Fort (iD

Correction to: Nature Photonics https://doi.org/10.1038/s41566-020-00749-9, published online 25 January 2021.

In the version of this Article originally published, Marion Bardou was mistakenly affiliated with the Centre de Biologie Structurale, CNRS, INSERM, Université de Montpellier, Montpellier, France; the affiliation has now been corrected to Université Paris-Saclay, CNRS, Institut des Sciences Moléculaires d’Orsay, Orsay, France.

Published online: 23 February 2021

https://doi.org/10.1038/s41566-021-00781-3

(c) The Author(s), under exclusive licence to Springer Nature Limited 2021 